\title{
Haematological Manifestations of Covid-19 and Emerging Immunohaematological Therapeutic Strategies
}

\author{
Nipun Bawiskar1 ${ }^{1}$, Amol Andhale², Vidyashree Hulkoti³ ${ }^{3}$, Sourya Acharya ${ }^{4}$, Samarth Shukla ${ }^{5}$
}

1,2, 3, 4 Department of Medicine, Datta Meghe Institute of Medical Sciences (Deemed to Be University), Sawangi Meghe, Wardha, Maharashtra, India. ${ }^{5}$ Department of Pathology, Datta Meghe Institute of Medical Sciences (Deemed to Be University), Sawangi Meghe, Wardha, Maharashtra, India.

\section{ABSTRACT}

Sars-CoV2 started as pneumonia of unknown aetiology in Wuhan, China. Considered primarily to be a respiratory pathogen, Covid-19 is now identified as a systemic infection with major effects on the haematopoietic system. Lymphopenia, peak platelet / lymphocyte ratio and neutrophil / lymphocyte ratio are some of the parameters that could be considered as prognostic markers of the disease. Disseminated intravascular coagulation along with elevated D-dimer levels are commonly encountered and are usually associated with a worsening clinical picture. IL-6, C reactive protein and lactate dehydrogenase with high serum prolactin and serum ferritin levels project a dismal outcome. Venous thromboembolism occurs in both ambulatory and bed ridden patients making thrombo-prophylaxis with LMWH (Low Molecular Weight Heparin) popular. This review article deals with the haematological manifestations of Covid-19 and the emerging therapies in relation with the same.

\section{KEY WORDS}

Covid-19, D-Dimer, IL-6, LMWH.
Corresponding Author: Dr. Sourya Acharya.

Professor,

Department of Medicine,

Datta Meghe Institute of Medical Sciences (Deemed to Be University),

Sawangi Meghe, Wardha,

Maharashtra, India.

E-mail: souryaacharya74@gmail.com

DOI: $10.14260 / j e m d s / 2020 / 763$

How to Cite This Article:

Bawiskar N, Andhale A, Hulkoti V, et al. Haematological manifestations of COVID19 and emerging immunohematological theraputic strategies. J Evolution Med Dent Sci 2020;9(46):3489-3494, DOI: $10.14260 / \mathrm{jemds} / 2020 / 763$

Submission 17-06-2020,

Peer Review 01-10-2020,

Acceptance 07-10-2020,

Published 16-11-2020.

Copyright (C) 2020 Nipun Bawiskar et al. This is an open access article distributed under Creative Commons Attribution License [Attribution 4.0 International (CC BY 4.0)] 


\section{BACKGROUND}

Covid-19 is a disease entity caused by SARS-CoV2 that started in Wuhan, the capital of Hubei province in China as a cluster of pneumonia cases of unknown aetiology. ${ }^{1}$ Initially spreading to other areas in China and Asia it has now come to dominate the world causing significant morbidity and mortality along its way. It is transmitted from one person to another via droplets and direct human-to-human contact. On entering the host it binds to certain receptors like angiotensin converting enzyme2 receptor (for which it has high affinity) and an alternate receptor CD209L. ACE 2 receptors are mainly present on the epithelium of trachea, bronchi, alveoli and macrophages. The virus enters the cells and begins to replicate following which mature virions are released. These in turn infect other cells causing initiation of a wide array of symptoms as the cycle continues. ${ }^{2,3}$ Chiefly thought of as a respiratory pathogen, emerging data has now come to suggest that Covid-19 is a systemic disease involving the gastrointestinal, cardiovascular, neurological, immune and haematopoietic systems as well.4,5,6 Research indicates that mortality is significantly higher in older individuals with comorbidities but younger individuals may also succumb if they present with lethal complications like DIC (Disseminated Intravascular Coagulation) and myocarditis. 7,8

\section{Blood Counts and Biochemistry Findings}

In the initial phase of the disease patients presents with nonspecific symptoms and a picture suggestive of hyperactivity followed by depletion of CD8 and T cells.9,10 Yang et al studied 52 critically ill patients and found that about $85 \%$ had lymphopenia ${ }^{11} \mathrm{~A}$ similar blood picture was seen in the ICU patients studied in Singapore $(p<0.0001) .{ }^{12}$ Lymphopenia was more severe in patients who ultimately succumbed to the disease. ${ }^{13}$ This was also apparent in studies conducted in The United states of America. ${ }^{14,15}$ Qin et al and Deng et al reported decreased lymphocyte / WBC ratio in those with severe disease.10,16 High leukocytes, low platelets and low lymphocytes are found in patients with myocardial injury. 17,18 In Wuhan 187 patients were evaluated and were found to have high troponin $\mathrm{T}$ levels associated with leukocytosis, lymphopenia and increased neutrophil counts. ${ }^{18}$ Based on a meta-analysis involving 9 studies thrombocytopenia is directly associated with severity of SARS-CoV2 infection. ${ }^{19} \mathrm{~A}$ peak in platelet count during the course of the disease was linked with a worse outcome, ${ }^{20}$ cytokine storm causes platelet activation, which in turn results in a high platelet to lymphocyte ratio now considered a prognostic marker. ${ }^{20}$

In accordance with a study conducted in China raised CRP, procalcitonin and LDH was found in $60.7 \%, 5.5 \%$ and $41 \%$ of the cases respectively. ${ }^{21}$ Zhou et al studied 191 patients and found higher levels of LDH, IL- 6 and serum ferritin in those that succumbed. ${ }^{22}$ Elevated LDH levels were indicative of the need for ICU (Intensive Care Unit) support, imminent ARDS (Acute Respiratory Distress Syndrome) and a higher risk of death. ${ }^{11,12,23}$ Raised CRP levels are also linked with the same, in addition to raised troponin $\mathrm{T}$ levels and myocardial injury. ${ }^{16,17,23}$ A positive correlation was found between serum ferritin levels, the risk of development of ARDS and probable death. ${ }^{22,23}$ IL-6 levels were found to demonstrate a similar likelihood.

\section{Coagulation Complications}

Elevated D-dimer levels were found in around $36 \%$ of the total number of cases assessed in a study in China. ${ }^{24}$ Those with high pro thrombin time and D dimer levels on admission were more likely to require ICU support during their hospital stay. 25 Wang et al. demonstrated the same in his analysis. ${ }^{13}$

Those with cardiac disorders are more likely to develop coagulation disorders as compared to those without cardiac involvement. ${ }^{17}$ Raised D-dimer, troponin $\mathrm{T}$ and a deranged coagulation profile were associated with increased risk of death and ARDS. ${ }^{22,23,26}$ Sequential rise in D-dimer, raised fibrin degradation products, APTT and PT were apparent among non survivors. 7,22 Therefore disseminated intravascular coagulation and D-dimer elevation are seen with severe SARSCoV2 infection. ${ }^{27}$ Endothelial dysfunction and immune deregulation play a part in the pathophysiology of the disease. ${ }^{28}$ In acutely ill hospitalized patients the rate of symptomatic VTE (Venous Thrombo-Embolism) is up to 10 $\% .{ }^{29}$

The risk of VTE goes up in the presence of cardiovascular risk factors and diseases, acute inflammatory states, prolonged immobilization, classical genetic thrombophilia and in past history of VTE. Increase in blood viscosity occurs as a result of release of certain hormones, immunoglobulins and inflammatory mediators in acutely ill patients. Mechanical ventilation, surgery and central venous catheterization cause vascular endothelial damage. A combination of these results in DVT (Deep Vein Thrombosis) and could lead to pulmonary embolism. Thromboprophylaxis is hence important and can be used prophylactically in these patients. ${ }^{30}$ Early diagnosis and treatment is important in patients who develop PE to prevent morbidity and mortality. D-dimer, USG venous doppler, bedside echo etc. can be used in patients with PE / DVT. CT (Computed Tomography) pulmonary angiography confirmed cases of PE (Pulmonary Embolism) had higher D-dimer levels as compared to those without PE. ${ }^{31}$

Unfractioned heparin or low molecular weight heparin are preferred over direct oral anticoagulants due to drug-drug interaction with concomitant antiviral and antibacterial treatment. ${ }^{32}$ Antithrombotic effect may be reduced or bleeding risk may increase if treatments interfere with CYP3A4 and / or P-gp pathways. Tang et al demonstrated the efficacy of LMWH in patients with markedly elevated D-dimer levels or those meeting the criteria for DIC.33 Heparin induced thrombocytopenia must be looked for in patients treated with heparin using 4T score (thrombocytopenia, timing of fall in platelet count, thrombosis and other causes of thrombocytopenia). The incidence has not been looked into but there is increased risk given immune dis-regulation, neutrophil extracellular traps, platelet factor 4 release and inflammatory syndrome.

\section{MANAGEMENT OF COVID-19 PATIENTS}

There are 4 Important Aspects in the Management of Covid-19 Patients

1. Identifications of patients at risk

2. Early diagnosis and follow up of DIC using ISTH score (platelet count, PT, fibrinogen, D-dimer, anti-thrombin and protein $\mathrm{C}$ activity monitoring). 
3. Optimization of thromboprophylaxis regimen and LMWH are first line choice drugs

4. Anti-inflammatory properties of LMWH are added benefit in Covid-19 patients and the possible need of integrating other antithrombotic treatment like anti-thrombin and recombinant thrombomodulin are helpful. ${ }^{34}$

\section{Blood and Haematopoietic Stem Cell Donation}

As a result of panic and insecurity surrounding Covid-19, blood donations have decreased. ${ }^{35} \mathrm{~A}$ similar scenario has been observed with stem cell donation. ${ }^{36}$ With rise in the number of critically ill patients it is important to maintain blood donations and hence spread awareness regarding maintenance of adequate national blood supply. ${ }^{37}$

\section{Cytokine Storm}

In early stages of SARS-CoV infection there is release of cytokines and chemokines from macrophages, epithelial cells and dendritic cells. Later low levels of interferons and high levels of chemokines (CCL-5, CCL-2 and CCL-3) and cytokines (IL-6, TNF alpha, IL-1 beta) are found. ${ }^{38-40}$ MERS-CoV infects THP-1 cells, monocyte derived macrophages and epithelial cells and causes release of chemokines and pro inflammatory cytokines similar to those induced by SARS-CoV. ${ }^{41,42}$ Raised chemokines and cytokines are associated with higher number of monocytes \& neutrophils in both lungs and in peripheral blood therefore implicating their role in lung pathology. $43,44,45$ Viral infections cause production of INF- $\alpha / \beta$ or INF-I. In early viral infection, INF-I plays a key role. ${ }^{46,47}$ T-helper cells are activated due to inflammatory cytokines that in turn activates specific immunity. Cytokine storm has positive correlation with the severity of the disease. ${ }^{48}$ Development and progression of ARDS is closely related to cytokine storm as a result of pulmonary and interstitial tissue damage caused due to non-specific cellular infiltration. It is also responsible for extra pulmonary multiple organ failure. ${ }^{49-52}$

\section{IF N- $\lambda$}

IFN- $\lambda$ inhibits recruitment of neutrophils, decreases macrophage medicated pro-inflammatory activity of IFN- $\alpha \beta$ and activates epithelial cells. ${ }^{53,54}$ Antiviral genes are stimulated in the epithelium, which in turn stimulate the human immune system. Interferons are beneficial by improving clinical symptoms but don't affect mortality rates. $55-57$

\section{Corticosteroid Therapies}

Corticosteroids suppress inflammation and are immunemodulators. They relieve fever, improve oxygenation and reduce radiation infiltration of lung. ${ }^{58,59,60}$ A study involving patients with severe SARS (Severe Acute Respiratory Syndrome) revealed decrease in mortality rates with shortened hospital stay in people administered with steroids. There is evidence to suggest that early treatment of SARS with glucocorticoids increases the plasma viral load in non-ICU patients causing aggravation of the disease.58 Early administration of glucocorticoids inhibits immune defence mechanism in the body thereby increasing the viral load. Timely administration prevents ARDS and protects the functions of the patients' organs. High doses may delay clearance of coronavirus due to immunosuppression.

\section{Intravenous Immunoglobulin (IVIG)}

Chen et al. studied 99 patients in Wuhan and found that $27 \%$ of them has received IVIG. ${ }^{61}$ It has dual effects causing immune modulation and immune substitution but requires further studies to confirm its efficacy.

\section{IL-1 Antagonists}

IL-33, IL-1 $\beta$ and IL-18 are released during cytokine storm. IL$1 \beta$ antagonist-Anakinra is used to treat cytokine storm caused by infection. The effects need to be verified by clinical trials and animal experimentation. ${ }^{62}$

\section{IL- 6 Antagonists}

Tocilizumab is an IL-6 antagonist and acts as an immunosuppressant. It is used in severely ill patients with lung lesions and elevated IL-6 levels. ${ }^{63}$ This was used in a study conducted in China where the initial dose was $4-8 \mathrm{mg} / \mathrm{kg}$, infused over 1 hour. Those that responded with poor efficacy were given an additional dose after 12 hours. A maximum of 2 doses were given.

\section{TNF (Tumour Necrosis Factor) Blockers}

Tumour necrosis factor is a contributing factor for cytokine storm. Anti TNF therapy has improved survival in people with sepsis. $^{64}$ In animal models it has been observed that TNF contributes to impaired $t$ cell response and acute lung injury and neutralization of TNF activity provides protection and decreases morbidity and mortality. 65 TNF antagonists are currently not used in the treatment of Covid-19 but their use requires further study.

\section{IF $N-\alpha \beta$ Inhibitors}

IFN- $\alpha \beta$ increases recruitment of mononuclear macrophages, other innate immune cells and limits viral replication. Proper timing is required to achieve desired response with interferon therapy. Animal models have shown protective response initially with delayed therapy causing an imbalance in the immune response. IFN- $\alpha \beta$ receptor antagonists can be used in later stages to prevent excess inflammatory responses. ${ }^{66}$

\section{Stem Cell Therapy}

Mesenchymal cells have immune regulatory and antiinflammatory function with a potential for multi directional differentiation and self-renewal. They induce differentiation in regulatory $\mathrm{T}$ cell subsets, anti-inflammatory macrophages and inhibit abnormal activation of $\mathrm{T}$ cells and macrophages. Stem cell therapy also inhibits the secretion of IL-12, IFN- $\gamma$ TNF- $\alpha$ and IL- 6.67,68 They can also secrete VEGF (Vascular Endothelial Growth Factor), keratinocyte growth factor, hepatocyte growth factor and IL-10 to promote regeneration, resist fibrosis and relieve ARDS.69

\section{Blood Purification Treatments}

This therapy can be used in critical patients in early and middle stages of the disease. They remove pro inflammatory 
mediators from circulation and thus block cytokine storm Academician Li Lan-Juan introduced the artificial liver technology that can be used to eliminate pro inflammatory cytokines on a large scale. ${ }^{70}$ Renal replacement therapy is another example of the same. ${ }^{71}$

\section{Inhibitors of Mononuclear Macrophage Recruitment and Function}

Large amount of inflammatory cell were found in the autopsy of Covid-19 patients. $^{72}$ Decreasing the recruitment of mononuclear macrophages by (siRNA) mediated silencing of $\mathrm{C}-\mathrm{C}$ chemokine receptor type 2 may improve the outcome in the disease as suggested by a few animal experiments. ${ }^{73,74}$ Toll-like receptor antagonists are able to alleviate cytokine storm caused by SARS-Cov2. Toll-like receptor agonists demonstrate a strong inflammatory response when used.

\section{Strengthening of the Vascular Barrier}

Cytokine storm causes an increase in the vascular permeability. In animal infection models of H5N1 virus and sepsis there was an improvement in the vascular permeability with activation of the endothelial Slit-Robo4 pathway therefore decreasing the effect of cytokine storm. ${ }^{75}$

\section{Convalescent Plasma Therapy}

One of the promising remedies developing is Convalescent Plasma (CP) or immune plasma. CP is plasma obtained from a recovered individual (e.g.: those infected with SARS CoV-2 i.e. human antieSARS-CoV-2 plasma), which is then transfused into newly infected patients as post-exposure prophylaxis. ${ }^{76}$ Unlike immunoglobulin (IgG) derived antibodies such as plasma-derived monoclonal antibodies, $\mathrm{CP}$ is a passive antibody treatment that has demonstrated considerable effectiveness as a neutralizing antibody against other coronavirus epidemics. Antibodies derived from CP can neutralize a virus by preventing replication (e.g. by supplementing activation or phagocytosis) or binding without interfering with replication.

\section{CONCLUSIONS}

Covid-19 therefore has significant implication on haematological parameters. Emerging therapies derived from blood and blood products are being researched. Stem cell therapy, plasma therapy etc. are promising modalities that could possibly decrease the morbidity and mortality associated with SARS-CoV2 infection. Future prospects of such therapies could be potential turning points in its management.

Financial or other competing interests: None.

Disclosure forms provided by the authors are available with the full text of this article at jemds.com.

\section{REFERENCES}

[1] Zhu N, Zhang D, Wang W, et al. A novel coronavirus from patients with pneumonia in China, 2019. N Engl J Med 2020;382(8):727-33.

[2] Chan JFW, Yuan S, Kok KH, et al. A familial cluster of pneumonia associated with the 2019 novel coronavirus indicating person-to-person transmission: a study of a family cluster. Lancet 2020;395(10223):514-23.

[3] $\mathrm{Xu} \mathrm{X}$, Chen P, Wang J, et al. Evolution of the novel coronavirus from the ongoing Wuhan outbreak and modeling of its spike protein for risk of human transmission. Sci China Life Sci 2020;63(3):457-60.

[4] Driggin E, Madhavan MV, Bikdeli B, et al. Cardiovascular considerations for patients, health care workers, and health systems during the COVID-19 Pandemic. J Am Coll Cardiol 2020;75(18):2352-71.

[5] Bangash MN, Patel J, Parekh D. COVID-19 and the liver: little cause for concern. Lancet Gastroenterol Hepatol 2020;5(6):529-30.

[6] Mehta P, McAuley DF, Brown M, et al. COVID-19: consider cytokine storm syndromes and immunosuppression. Lancet 2020;395(10229):1033-4.

[7] Tang N, Li D, Wang X, et al. Abnormal coagulation parameters are associated with poor prognosis in patients with novel coronavirus pneumonia. J Thromb Haemost 2020;18(4):844-7.

[8] Madjid M, Safavi-Naeini P, Solomon SD, et al. Potential effects of coronaviruses on the cardiovascular system: a review. JAMA Cardiol 2020;5(7):831-40.

[9] Zheng HY, Zhang M, Yang CX, et al. Elevated exhaustion levels and reduced functional diversity of $\mathrm{T}$ cells in peripheral blood may predict severe progression in COVID- 19 patients. Cell Mol Immunol 2020;17(5):541-3.

[10] Qin C, Zhou L, Hu Z, et al. Dysregulation of immune response in patients with COVID-19 in Wuhan, China. Clin Infect Dis 2020;71(15):762-8.

[11] Yang X, Yu Y, Xu J, et al. Clinical course and outcomes of critically ill patients with SARS-CoV-2 pneumonia in Wuhan, China: a single-centered, retrospective, observational study. Lancet Respir Med 2020;8(5):47581.

[12] Fan BE, Chong VCL, Chan SSW, et al. Hematologic parameters in patients with COVID-19 infection. Am J Hematol 2020;95(6):E131-4.

[13] Wang D, Hu B, Hu C, et al. Clinical characteristics of 138 hospitalized patients with 2019 novel coronavirusinfected pneumonia in Wuhan, China. JAMA 2020;323(11):1061-9.

[14] Arentz M, Yim E, Klaff L, et al. Characteristics and outcomes of 21 critically ill patients with COVID-19 in Washington State. JAMA 2020;323(16):1612-4.

[15] Bhatraju PK, Ghassemieh BJ, Nichols M, et al. COVID-19 in critically ill patients in the seattle region - case series. $\mathrm{N}$ Engl J Med 2020;382(21):2012-22.

[16] Deng Y, Liu W, Liu K, et al. Clinical characteristics of fatal and recovered cases of coronavirus disease 2019 (COVID19) in Wuhan, China: a retrospective study. Chin Med J (Engl) 2020;133(11):1261-7.

[17] Shi S, Qin M, Shen B, et al. Association of cardiac injury with mortality in hospitalized patients with COVID-19 in Wuhan, China. JAMA Cardiol 2020;5(7):802-10.

[18] Guo T, Fan Y, Chen M, et al. Cardiovascular implications of fatal outcomes of patients with coronavirus disease 2019 (COVID-19). JAMA Cardiol 2020;5(7):811-8. 
[19] Lippi G, Plebani M, Henry BM. Thrombocytopenia is associated with severe coronavirus disease 2019 (COVID19) infections: a meta-analysis. Clin Chim Acta 2020;506:145-8.

[20] Qu R, Ling Y, Zhang YH, et al. Platelet-to-lymphocyte ratio is associated with prognosis in patients with coronavirus disease-19. J Med Virol 2020;92(9):1533-41.

[21] Guan WJ, Ni ZY, Hu Y, et al. Clinical characteristics of coronavirus disease 2019 in China. N Engl J Med 2020;382:1708-20.

[22] Zhou F, Yu T, Du R, et al. Clinical course and risk factors for mortality of adult inpatients with COVID-19 in Wuhan, China: a retrospective cohort study. Lancet 2020;395(10229):1054-62.

[23] Wu C, Chen X, Cai Y, et al. Risk factors associated with acute respiratory distress syndrome and death in patients with coronavirus disease 2019 pneumonia in Wuhan, China. JAMA Intern Med 2020;180(7):934-43.

[24] Chen N, Zhou M, Dong X, et al. Epidemiological and clinical characteristics of 99 cases of 2019 novel coronavirus pneumonia in Wuhan, China: a descriptive study. Lancet 2020;395(10223):507-13.

[25] Huang C, Wang Y, Li X, et al. Clinical features of patients infected with 2019 novel coronavirus in Wuhan, China. Lancet 2020;395(10223):497-506.

[26] Guo T, Fan Y, Chen M, et al. Cardiovascular implications of fatal outcomes of patients with coronavirus disease 2019 (COVID-19). JAMA Cardiol 2020;5(7):811-8.

[27] Lippi G, Favaloro EJ. D-dimer is associated with severity of coronavirus disease 2019: a pooled analysis. Thromb Haemost 2020;120(5):876-8.

[28] Lillicrap D. Disseminated intravascular coagulation in patients with 2019-nCoV pneumonia. J Thromb Haemost 2020;18(4):786-7.

[29] Kahn SR, Lim W, Dunn AS, et al. Prevention of VTE in nonsurgical patients: antithrombotic therapy and prevention of thrombosis, 9th ed: American College of Chest Physicians Evidence-Based Clinical Practice Guidelines. Chest 2012;141(2 Suppl):e195S-226S.

[30] Witt DM, Nieuwlaat R, Clark NP, et al. American Society of Hematology 2018 guidelines for management of venous thromboembolism: optimal management of anticoagulation therapy. Blood Adv 2018;2(22):3257-91.

[31] Chen J, Wang X, Zhang S, et al. Findings of acute pulmonary embolism in COVID- 19 patients. Lancet Infect Dis 2020. DOI: $10.2139 /$ ssrn.3548771

[32] Thachil J, Tang N, Gando S, et al. ISTH interim guidance on recognition and management of coagulopathy in COVID19. J Thromb Haemost 2020;18(5):1023-6.

[33] Tang N, Bai H, Chen X, et al. Anticoagulant treatment is associated with decreased mortality in severe coronavirus disease 2019 patients with coagulopathy. J Thromb Haemost 2020 18(5):1094-9.

[34] Terpos E, Ntanasis-Stathopoulos I, Elalamy I, et al. Hematological findings and complications of COVID-19. Am J Hematol 2020;95(7):834-47.

[35] Pagano MB, Hess JR, Tsang HC, et al. Prepare to adapt: blood supply and transfusion support during the first 2 weeks of the 2019 novel coronavirus (COVID-19) pandemic affecting Washington State. Transfusion 2020;60(5):908-911.
[36] Szer J, Weisdorf D, Querol S, et al. The impact of COVID-19 on the provision of donor hematopoietic stem cell products worldwide: collateral damage. Bone Marrow Transplant 2020;55(10):2043-4.

[37] WHO. Maintaining a safe and adequate blood supply during the pandemic outbreak of coronavirus disease (COVID-19). WHO reference number: WHO/2019nCoV/BloodSupply/2020.1. World Health Organization 2020.

[38] Law HKW, Cheung CY, Ng HY, et al. Chemokine upregulation in SARS-coronavirus-infected, monocytederived human dendritic cells. Blood 2005;106(7):236674.

[39] Cheung CY, Poon LLM, Ng IHY, et al. Cytokine responses in severe acute respiratory syndrome coronavirus-infected macrophages in vitro: possible relevance to pathogenesis. J Virol 2005;79(12):7819-26.

[40] Lau SKP, Lau CCY, Chan KH, et al. Delayed induction of proinflammatory cytokines and suppression of innate antiviral response by the novel Middle East respiratory syndrome coronavirus: implications for pathogenesis and treatment. J Gen Virol 2013;94(Pt 12):2679-90.

[41] Tynell J, Westenius V, Rönkkö E, et al. Middle East respiratory syndrome coronavirus shows poor replication but significant induction of antiviral responses in human monocyte-derived macrophages and dendritic cells. J Gen Virol 2016;97(2):344-55.

[42] Zhou J, Chu H, Li C, et al. Active replication of Middle East respiratory syndrome coronavirus and aberrant induction of inflammatory cytokines and chemokines in human macrophages: implications for pathogenesis. J Infect Dis 2014;209(9):1331-42.

[43] Kim ES, Choe PG, Park WB, et al. Clinical progression and cytokine profiles of middle east respiratory syndrome coronavirus infection. J Korean Med Sci 2016;31(11):1717-25.

[44] Min CK, Cheon S, Ha NY, et al. Comparative and kinetic analysis of viral shedding and immunological responses in MERS patients representing a broad spectrum of disease severity. Scientific Rep 2016;6:25359.

[45] Ng DL, Al Hosani F, Keating MK, et al. Clinicopathologic, immunohistochemical, and ultrastructural findings of a fatal case of middle east respiratory syndrome coronavirus infection in the United Arab Emirates, April 2014. Am J Pathol 2016;186(3):652-8.

[46] García-Sastre A, Biron CA. Type 1 interferons and the virus-host relationship: a lesson in détente. Science 2006;312(5775):879-82.

[47] Channappanavar R, Fehr AR, Zheng J, et al. IFN-I response timing relative to virus replication determines MERS coronavirus infection outcomes. J Clin Invest 2019;129(9):3625-39.

[48] Ranieri VM, Rubenfeld GD, Thompson BT, et al. Acute respiratory distress syndrome: the berlin definition. JAMA 2012;307(23):2526-33.

[49] Douda DN, Jackson R, Grasemann H, et al. Innate immune collectin surfactant protein D simultaneously binds both neutrophil extracellular traps and carbohydrate ligands and promotes bacterial trapping. J Immunol (Baltimore, Md: 1950) 2011;187(4):1856-65. 
[50] Parsons PE, Eisner MD, Thompson BT, et al. Lower tidal volume ventilation and plasma cytokine markers of inflammation in patients with acute lung injury. Crit Care Med 2005;33(1):1-6.

[51] Wang H, Ma S. The cytokine storm and factors determining the sequence and severity of organ dysfunction in multiple organ dysfunction syndrome. Am J Emerg Med 2008;26(6):711-15.

[52] Davidson S, McCabe TM, Crotta S, et al. IFN $\lambda$ is a potent anti-influenza therapeutic without the inflammatory side effects of IFN $\alpha$ treatment. EMBO Mol Med 2016;8(9):1099-112.

[53] Blazek K, Eames HL, Weiss M, et al. IFN- $\lambda$ resolves inflammation via suppression of neutrophil infiltration and IL-1 $\beta$ production. J Exp Med 2015;212(6):845-53.

[54] Arabi YM, Shalhoub S, Mandourah Y, et al. Ribavirin and interferon therapy for critically ill patients with middle east respiratory syndrome: a multicenter observational study. Clin Inf Dis 2019;70(9):1837-44.

[55] Omrani AS, Saad MM, Baig K, et al. Ribavirin and interferon alfa-2a for severe Middle East respiratory syndrome coronavirus infection: a retrospective cohort study. Lancet Infect Dis 2014;14(11):1090-5.

[56] Zumla A, Chan JFW, Azhar EI, et al. Coronaviruses - drug discovery and therapeutic options. Nat Rev Drug Discov 2016;15(5):327-47.

[57] Auyeung TW, Lee JSW, Lai WK, et al. The use of corticosteroid as treatment in SARS was associated with adverse outcomes: a retrospective cohort study. J Infect 2005;51(2):98-102.

[58] Ho JC, Ooi GC, Mok TY, et al. High-dose pulse versus nonpulse corticosteroid regimens in severe acute respiratory syndrome. Am J Resp Crit Care Med 2003;168(12):1449-56.

[59] Yam LYC, Lau ACW, Lai FYL, et al. Corticosteroid treatment of severe acute respiratory syndrome in Hong Kong. J Infect 2007;54(1):28-39.

[60] Chen RC, Tang XP, Tan SY, et al. Treatment of severe acute respiratory syndrome with glucosteroids: the Guangzhou experience. Chest 2006;129(6):1441-52.

[61] Shimabukuro-Vornhagen A, Gödel P, Subklewe M, et al. Cytokine release syndrome. J Immunother Cancer 2018;6(1):56.

[62] Tanaka T, Narazaki M, Kishimoto T. Immunotherapeutic implications of IL-6 blockade for cytokine storm. Immunotherapy 2016;8(8):959-70.
[63] Qiu P, Cui X, Sun J, et al. Antitumor necrosis factor therapy is associated with improved survival in clinical sepsis trials: a meta-analysis. Crit Care Med 2013;41(10):241929.

[64] McDermott JE, Mitchell HD, Gralinski LE, et al. The effect of inhibition of PP1 and TNF $\alpha$ signaling on pathogenesis of SARS coronavirus. BMC Syst Biol 2016;10(1):93.

[65] Davidson S, Maini MK, Wack A. Disease-promoting effects of type I interferons in viral, bacterial, and coinfections. J Interferon Cytokine Res 2015;35(4):252-64.

[66] Uccelli A, de Rosbo NK. The immunomodulatory function of mesenchymal stem cells: mode of action and pathways. Ann NY Acad Sci 2015;1351(1):114-26.

[67] Ben-Mordechai T, Palevski D, Glucksam-Galnoy Y, et al. Targeting macrophage subsets for infarct repair. J Cardiovascular Pharmacol Ther 2014;20(1):36-51.

[68] Lee JW, Fang X, Krasnodembskaya A, et al. Concise review: mesenchymal stem cells for acute lung injury: role of paracrine soluble factors. Stem Cells 2011;29(6):913-9.

[69] Xu K, Cai H, Shen Y, et al. Management of coronavirus disease-19 (COVID-19): the Zhejiang experience. Zhejiang Da Xue Xue Bao Yi Xue Ban 2020;49(1):147-57.

[70] Zuccari S, Damiani E, Domizi R, et al. Changes in cytokines, haemodynamics and microcirculation in patients with sepsis/septic shock undergoing continuous renal replacement therapy and blood purification with cytoSorb. Blood Purif 2020;49(1-2):107-13.

[71] Xu Z, Shi L, Wang Y, et al. Pathological findings of COVID19 associated with acute respiratory distress syndrome. Lancet Respirat Med 2020;8(4):420-2.

[72] Leuschner F, Courties G, Dutta P, et al. Silencing of CCR2 in myocarditis. Eur Heart J 2015;36(23):1478-88.

[73] Leuschner F, Dutta P, Gorbatov R, et al. Therapeutic siRNA silencing in inflammatory monocytes in mice. Nat Biotechnol 2011;29(11):1005-10.

[74] London NR, Zhu W, Bozza FA, et al. Targeting Robo4dependent slit signaling to survive the cytokine storm in sepsis and influenza. Sci Transl Med 2010;2(23):23ra19.

[75] Bloch EM, Shoham S, Casadevall A, et al. Deployment of convalescent plasma for the prevention and treatment of COVID-19. J Clin Invest 2020;130(6):2757-65.

[76] van Erp EA, Luytjes W, Ferwerda G, et al. Fc-mediated antibody effector functions during respiratory syncytial virus infection and disease. Front Immunol 2019;10:548. 